\title{
Local and synoptic mechanisms causing Southern California's Santa Ana winds
}

\author{
Mimi Hughes · Alex Hall
}

Received: 2 October 2008/Accepted: 8 August 2009/Published online: 25 August 2009

(C) The Author(s) 2009. This article is published with open access at Springerlink.com

\begin{abstract}
The atmospheric conditions that lead to strong offshore surface winds in Southern California, commonly referred to as Santa Ana winds, are investigated using the North American Regional Reanalysis and a 12-year, 6-km resolution regional climate simulation of Southern California. We first construct an index to characterize Santa Ana events based on offshore wind strength. This index is then used to identify the average synoptic conditions associated with Santa Ana events-a high pressure anomaly over the Great Basin. This pressure anomaly causes offshore geostrophic winds roughly perpendicular to the region's mountain ranges, which in turn cause surface flow as the offshore momentum is transferred to the surface. We find, however, that there are large variations in the synoptic conditions during Santa Ana conditions, and that there are many days with strong offshore flow and weak synoptic forcing. This is due to local thermodynamic forcing that also causes strong offshore surface flow: a large temperature gradient between the cold desert surface and the warm ocean air at the same altitude creates an offshore pressure gradient at that altitude, in turn causing katabatic-like offshore flow in a thin layer near the surface. We quantify the contribution of "synoptic" and "local thermodynamic" mechanisms using a bivariate linear regression model, and find that, unless synoptic conditions force strongly onshore
\end{abstract}

\section{Hughes $(\bowtie) \cdot$ A. Hall}

University of California, Los Angeles,

Box 951565, Los Angeles, CA 90095, USA

e-mail: mrhughes@ucla.edu

Present Address:

M. Hughes

Earth System Research Laboratory, Physical Sciences Division,

National Oceanic and Atmospheric Administration,

325 Broadway St, Boulder, CO 80005, USA winds, the local thermodynamic forcing is the primary control on Santa Ana variability.

Keywords Santa Ana winds - Katabatic winds . Regional climate

\section{Introduction}

The cool, moist fall and winter climate in Southern California is often disrupted by dry, hot days with strong winds blowing out of the desert. These "Santa Ana" winds are a dominant feature of the fall and wintertime climate of Southern California (Conil and Hall 2006), and have important human and ecological impacts. First, and most pronounced, is their effect on wildfires: following the hot, dry summer, the extremely low relative humidities and gusty strong winds that occur during Santa Anas introduce extreme fire risk which often culminates in wildfires with large economic loss (Westerling et al. 2004). The Santa Anas also influence the ocean off the coast of Southern California and Baja California, inducing cold filaments in sea-surface temperature and increasing biological activity (Castro et al. 2006; Trasviña et al. 2003) probably due to increased vertical mixing where winds are strongest $(\mathrm{Hu}$ and Liu 2003). These strong offshore wind events also transport large amounts of dust to the ocean, where dust can enhance biological activity (Hu and Liu 2003; Jickells et al. 2005).

Numerous studies have identified mechanisms causing strong terrain-intensified winds when large-scale/synoptic conditions are favorable (e.g., Durran 1990; Smith 1979, 1985; Klemp and Lilly 1975). When strong mid-tropospheric winds impinge on mountain tops in a stably stratified environment, gravity waves can transfer this mid-level 
momentum to the surface, resulting in strong lee-side surface winds. Two recent studies have also focused on flow acceleration in idealized gaps, and found that strong gap flow developed primarily because of downward mass and momentum fluxes, with strongest flows when geostrophic winds were parallel to the gap (Gaberšek and Durran 2004, 2006). These results provide a mechanism relating the synoptic scale pressure gradient to the strength of Santa Anas, and are somewhat consistent with the picture painted by previous research: Case studies have suggested that Santa Anas form because of an upper level northwest to southeast pressure gradient (Sommers 1978; Schroeder et al. 1964), with a high sea-level pressure anomaly in the Great Basin (Conil and Hall 2006; Raphael 2003).

While these studies provide a plausible mechanism for Santa Ana formation, no study has documented whether Santa Ana intensity scales with the large scale pressure gradient as one would expect. The tenuous statistical connection between Santa Ana frequency and larger-scale modes of variability (Conil and Hall 2006; Raphael 2003), as well as their peak December occurrence, 2 months before the climatological peak in synoptic disturbances (Hartmann 1994), hints that another, more local mechanism might play a role in their development. Given the very cold desert-surface air temperatures associated with Santa Anas (Conil and Hall 2006), another possibility is that a strong temperature gradient across the gap causes strong winds to develop at the surface in a gravity-current like response (Ball 1956; Mahrt 1982). The temperature gradient induces a hydrostatic pressure gradient pointing from the desert to the ocean, which is reinforced by the negative buoyancy of the cold air as it flows down the sloped surface of the major topographical gaps. This mechanism is similar to the one driving katabatic winds of Antarctica (Parish and Cassano 2003a; Barry 1992).

To identify the important processes controlling Santa Ana development, we need a dataset with a large enough spatial extent to represent synoptic conditions as well as high enough spatial resolution to resolve local dynamics. To represent synoptic conditions, we utilize the North American regional reanalysis (NARR), because it has a large enough spatial domain to capture North American synoptic features, and is high-quality when compared with other reanalysis products (Mesinger et al. 2006). However, at $32 \mathrm{~km}$ resolution, only the coarsest features of Southern California's terrain are resolved, resulting in a poor representation of the local dynamics (Conil and Hall 2006). To overcome this we downscale the Eta analysis to 6-km horizontal resolution using the Penn State/NCAR mesoscale model version 5, creating a fine-scale representation of the local dynamics. Figure 1 shows the NARR offshore surface winds at the exit of the largest gap in Southern

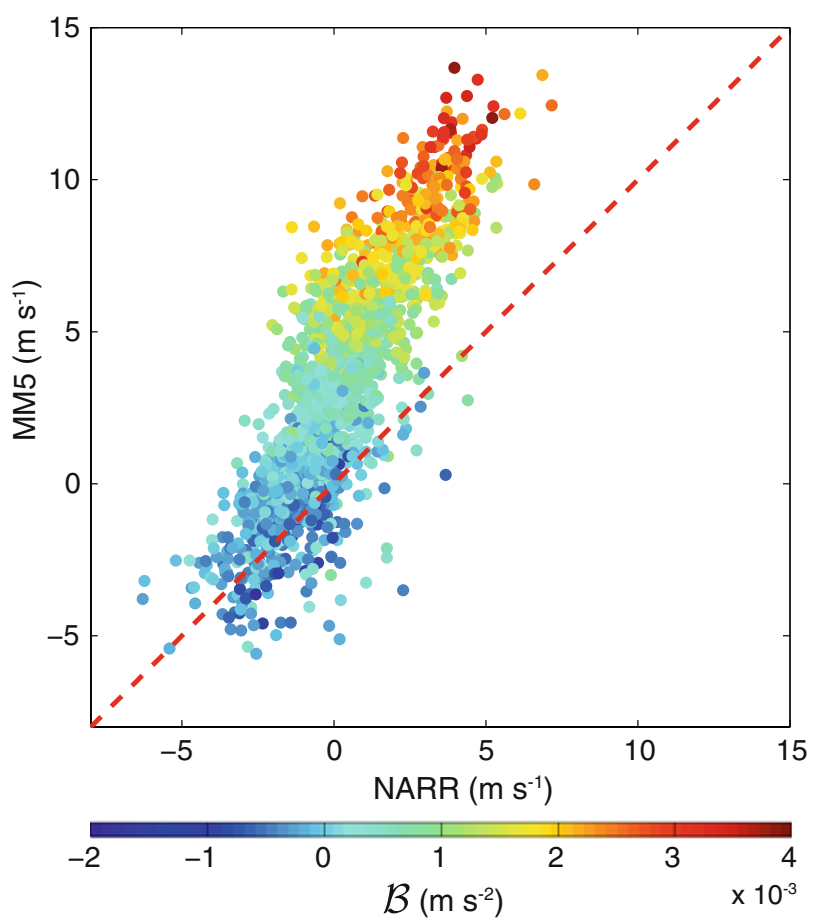

Fig. 1 Scatter plot of the daily NARR offshore $10 \mathrm{~m}$ wind at $34.12 \mathrm{~N}$, $118.83 \mathrm{~W}$ versus the MM5 offshore $10 \mathrm{~m}$ wind averaged over the 25 closest grid points, for days between October and March. The points are color coded by the magnitude of the buoyancy-induced pressure gradient force described in section 5 (reference colorbar is at bottom)

California's topography, where the winds during Santa Ana events are particularly strong, plotted against those from the MM5 simulation, averaged over the 25 closest gridpoints. The NARR dramatically underestimates the wind strength during days with strong offshore flow, suggesting it is incapable of representing SA conditions and justifying our usage of the high-resolution data.

This manuscript investigates the dynamics controlling the strength of Santa Ana winds, utilizing the NARR (Sect. 2.1 ) and a 12-year, $6 \mathrm{~km}$ dynamically downscaled atmospheric product (Sect. 2.2). We begin by constructing a daily index to quantify Santa Ana intensity (Sect. 3). The contributions of the two plausible mechanisms discussed above are explored in Sects. 4 and 5, and quantified using a linear bivariate regression model (Sect. 6), followed by a brief summary (Sect. 7).

\section{Data}

\subsection{North American regional reanalysis}

We provide a synoptic scale perspective with the North American Regional Reanalysis (NARR, Mesinger et al. 2006). The NARR is a $32 \mathrm{~km}$ resolution product that covers North America and part of the Pacific and Atlantic 
Oceans (Fig. 2). The time series begins in 1972, and is updated regularly to extend the dataset to the present. The NARR was created using the Eta model to downscale the NCEP Reanalysis, with additional data assimilation to improve the product. Mesinger et al. (2006) have shown that the NARR is a major improvement over the NCEP Reanalysis, and that it provides high quality estimations of coarse-scale features of atmospheric conditions such as pressure and synoptic-scale winds, especially in winter.

\subsection{MM5 simulation}

Identification of events and a local perspective on the dynamics will be given by a high resolution simulation created with the Penn State/NCAR mesoscale model version 5, release 3.6.0 (MM5 Grell et al. 1994). The $6 \mathrm{~km}$ domain was nested within an $18 \mathrm{~km}$ domain covering Southern California and parts of Arizona, Nevada, and Mexico, which was likewise nested within a $54 \mathrm{~km}$ domain encompassing most of the western US (Fig. 2, blue lines). At this resolution, all major mountain complexes in Southern California are represented, as are the Channel islands just off the coast. The number of gridpoints in each domain are $35 \times 36,37 \times 52$, and $55 \times 97$ for the 54,18 , and $6 \mathrm{~km}$ domains, respectively, and the nesting was twoway for both interior domains. Each domain has 23 vertical levels, with the vertical grid stretched to place the highest resolution in the lower troposphere. In the outer two domains, the Kain-Fritsch 2 (Kain 2002) cumulus parameterization scheme was used. In the $6 \mathrm{~km}$ domain only explicitly resolved convection could occur. In all domains, we used the MRF boundary layer scheme (Hong and Pan 1996), Dudhia simple ice microphysics (Dudhia 1989), and a radiation scheme simulating longwave and shortwave interactions with clear-air and cloud (Dudhia 1989).

The boundary conditions for the simulation come from NCEP's 40-km resolution Eta model analysis data available through the National Center for Atmospheric Research's GCIP archive; this dataset is very similar to the NARR, except it is an operational product and thus has reduced data assimilation. The time period covered in the simulation was from May 1995 to December 2006. Throughout this period, MM5 was initialized every 3 days at $18 \mathrm{Z}$ (10 am local time) and run for $78 \mathrm{~h}$, with the first $6 \mathrm{~h}$ being discarded as model spin-up. The interior boundary conditions and sea-surface temperatures were updated at each initialization, with the lateral boundary conditions updated continuously throughout the run. Thus the simulation in the 6-km nest acts as a reconstruction of the local atmospheric conditions based on known large scale atmospheric conditions.

We confirm the effectiveness of this downscaling technique in reconstructing the Santa Anas by showing the correlation between observed daily offshore surface winds with MM5 winds at the nearest gridpoint (Fig. 3), where we have defined 'offshore' as northeasterly. The correlations are larger than 0.4 in all but five of the 42 locations, and larger than 0.7 at 13 locations. This high degree of correspondence between the two datasets gives us a reasonable degree of confidence in the simulation's fidelity. In
Fig. 2 Domain of the NARR used in this paper. Colored contours show the surface geopotential height, in geopotential meters with contours every $800 \mathrm{~m}$, and the coastline is shown as the thin black line. The thin blue lines show the 3 domains of the MM5 downscaling; MM5 topography is superimposed in $6 \mathrm{~km}$ domain

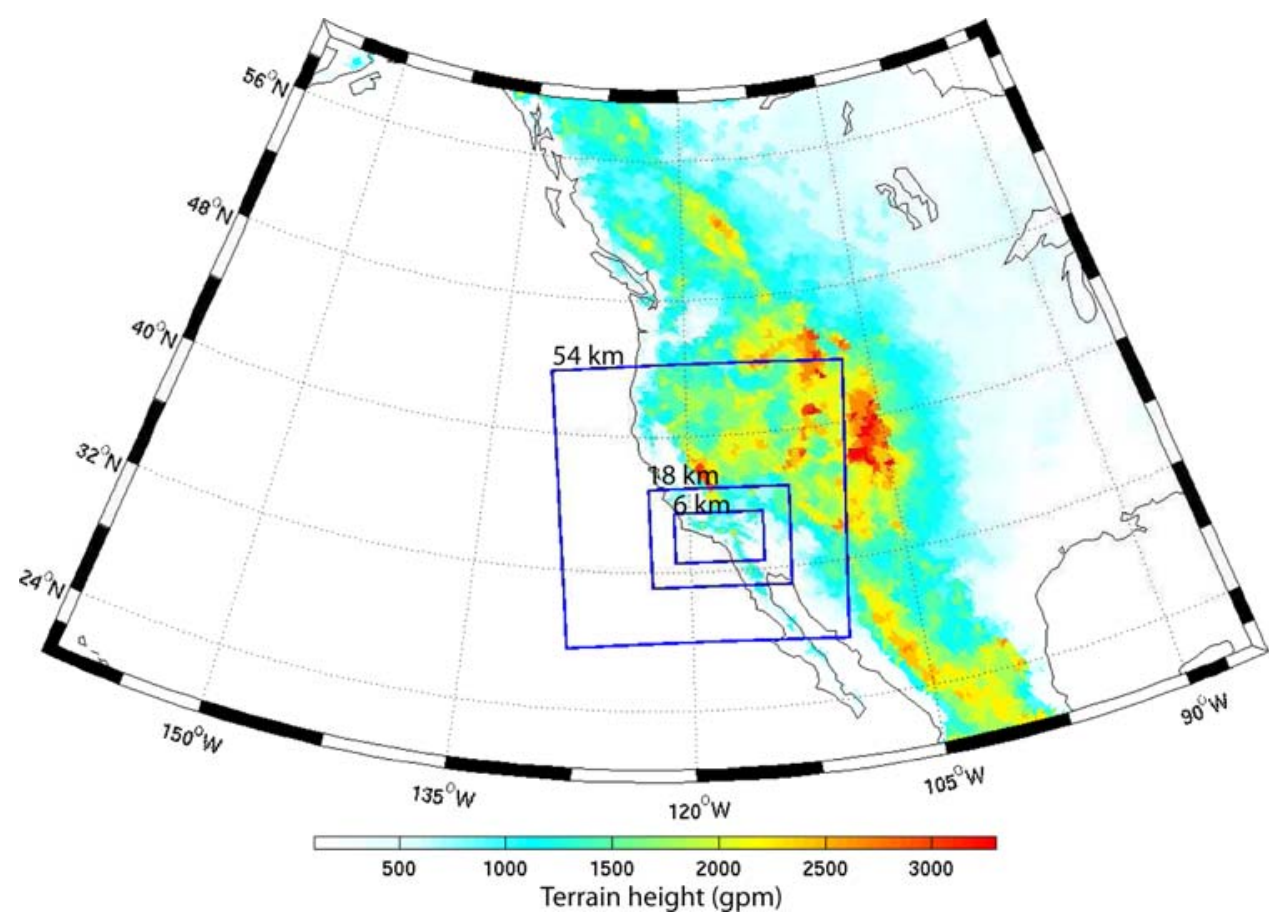




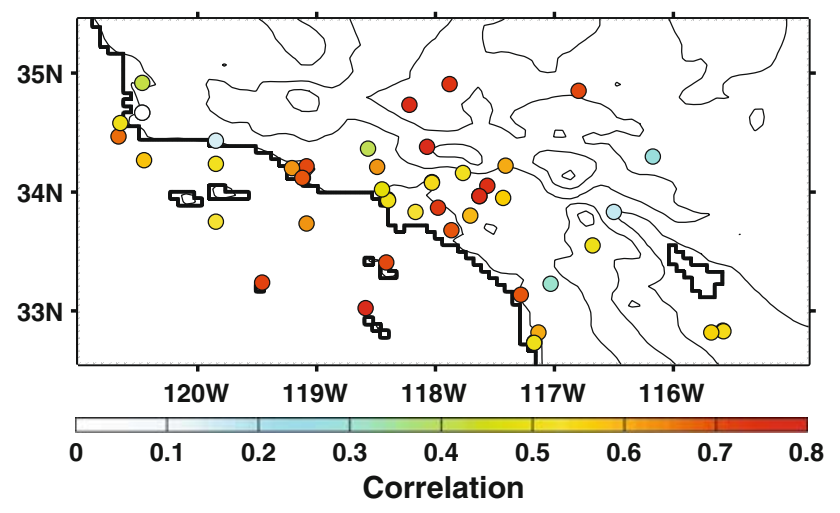

Fig. 3 Correlation of observed offshore component of wintertime daily winds with that from the MM5 simulation at the nearest gridpoint, on days when winds $2 \mathrm{~km}$ above sea level over the desert are offshore. Black contours show model terrain, plotted every $800 \mathrm{~m}$ starting at $100 \mathrm{~m}$. Thick black contour shows coastline at $6 \mathrm{~km}$ resolution

addition, two previous studies have also shown the simulation accurately reproduces circulation variability: Correlating the simulation's daily-mean winds with available point measurements, Conil and Hall (2006) verified that the simulation captures synoptic time-scale variability in the daily-mean wind speed and direction. In addition, Hughes et al. (2007) confirmed that this simulation was able to reproduce the observed diurnal cycles of wind and surface air temperature found in a network of 30 observation stations in the region.

\section{A Santa Ana index}

The first step in identifying the local and synoptic scale atmospheric conditions associated with Santa Ana (SA) winds is to create a SA index. In the past, this has been done in numerous ways. Two recent studies have used large scale surface pressure conditions, a high over the Great Basin and a low southwest of Los Angeles, to identify Santa Ana events (Miller and Schlegel 2006; Raphael 2003). Operational definitions combine this pressure gradient with two other parameters, the relative humidity in coastal Southern California, and wind direction in major mountain passes (Sommers 1978; Danielson 2007, personal communication). Conil and Hall (2006) used a mixture model cluster analysis of the daily mean wind anomalies to classify the winter circulation into three regimes, one of which was Santa Ana events.

For this study, we seek a SA index that does not introduce assumptions about large scale mechanisms possibly causing Santa Anas. The operational and large-scale definitions do not meet this criterion. Further, we also seek an index that gives information about SA intensity. The cluster model classification technique gives no indication about the strength of the offshore flow and rather simply classifies a day as experiencing Santa Ana conditions or not. Since no previous metric meets our needs, we develop a new SA index based on the magnitude of a spatially extensive offshore wind in the local circulation.

Figure 4a shows the composite 'Santa Ana cluster' surface winds, where the cluster analysis is performed using the same algorithm as Conil and Hall (2006). The composite SA cluster wind field exhibits characteristics we expect for SA events: strong offshore (that is, roughly northeasterly) winds throughout most of Southern California, with the strongest winds on the leeward slopes of the mountains and through the gaps in the topography, most notably across the Santa Monica mountains. We create a SA index (SAt, Fig. 4b) by averaging the offshore wind strength through the largest gap (Fig. 4a, blue box); the winds in this region show particularly good agreement with the observations (Fig. 3). For the compositing technique used in Sect. 4, a 'Santa Ana day' (SAD) is classified as a day with SAt greater than $5 \mathrm{~m} \mathrm{~s}^{-1}$ (black dashed line, Fig. 4b).

(a) Average winds of Santa Ana cluster

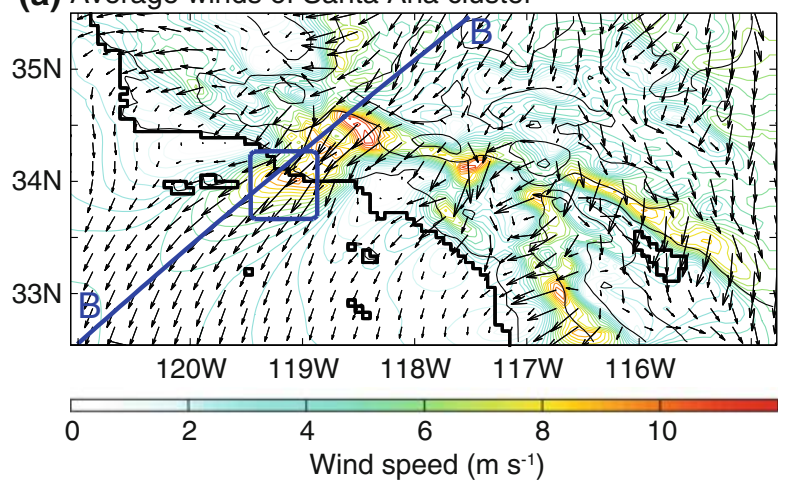

(b) Santa Ana time index

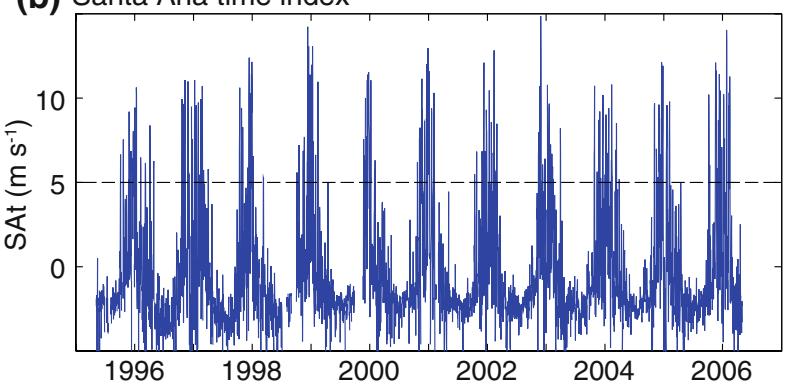

Fig. 4 a Average winds for the Santa Ana cluster, similar to those in Conil and Hall (2006). Arrows show total wind, color contours show wind speed. Only every third grid point is plotted for clarity. Line $B B$ shows location of cross section shown in Fig. 8. Blue box shows area of average used to compute SAt. Terrain is shown as in Fig. 3. b Magnitude of the Santa Ana index (SAt) for entire 12 year time period. Thin dashed black line shows $\mathrm{SAt}=5$, the threshold used to define a Santa Ana in composites 
Our index has a very strong seasonality (Fig. 4b), with peak occurrence in December and no strong offshore winds from April to early September. This agrees with previous indices of SA occurrence (Conil and Hall 2006; Raphael 2003). Because of this strong seasonality, from here on we only consider days between October and March and refer to them as 'winter' days.

\section{Synoptic controls}

Previous studies identified large-scale mid-tropospheric synoptic conditions as the driver of SAs (e.g., Sommers 1978). These results are consistent with the more theoretical findings of Gaberšek and Durran (2006), who, using idealized topography, found strong gap winds for a range of near-mountain-peak geostrophic wind conditions, with the strongest gap and downslope winds when the geostrophic flow near the mountain tops was aligned approximately parallel to the gap. They found that, as long as the atmosphere is vertically stably stratified with a nondimensional mountain height close to one-which occurs on a large proportion of SADs (not shown) - gravity waves can transfer the upper-level, along-gap momentum to the surface, causing strong gap flows.

To test whether this mechanism is at work in the case of SAs, we examine how tightly coupled synoptic conditions are to SA winds. Figure 5a shows the composite $700 \mathrm{hPa}$ geopotential height (GPH) anomaly for days with SAt greater than $5 \mathrm{~m} \mathrm{~s}^{-1}$. The pattern is a high centered just off the coast of Oregon. The geostrophic winds associated with this GPH anomaly would be northeasterly over Southern California-exactly the direction of our 'offshore' flow, and roughly perpendicular to the coastal topography; approximate magnitudes of associated geostrophic winds are given in the Fig. 5 caption. This suggests local surface winds are indeed offshore because there are synopticallyforced offshore winds near the peaks of the topography. The relationship between the local surface offshore winds and the mid-tropospheric flow can be seen in Fig. 6, which shows the meridional and zonal components of the MM5 winds $2 \mathrm{~km}$ above sea level averaged over an area within the Mojave Desert (hereafter $2 \mathrm{~km}$ desert winds) for each day, with points color-coded by the magnitude of SAt. The vector drawn from the origin (Fig. 6, large black box) to each point shows the speed and direction for each day, whereas the shortest distance between each point and the blue dashed line shows the magnitude of the offshore component of the wind. From Fig. 6, we see that almost all SA days occur when the $2 \mathrm{~km}$ desert winds have an offshore component. If we assume that the $2 \mathrm{~km}$ desert winds are nearly geostrophic, this means that there is a high to low pressure anomaly from approximately NW to SE of Southern California, consistent with our composite GPH anomaly in Fig. 5a.

While these results suggest the mechanisms of Gaberšek and Durran (2006) might be relevant, closer inspection reveals strong variations in SAt not related to the large-
Fig. 5 a Mean $700 \mathrm{hPa}$ geopotential height anomaly for days with the Santa Ana index greater than $5 \mathrm{~m} \mathrm{~s}^{-1}$. High geopotential height anomaly days are defined as days where the spatial average height anomaly in the region within the thin blue line is above $70 \mathrm{~m}$. b Mean $700 \mathrm{hPa}$ geopotential height anomaly for days with a high geopotential height anomaly and with SAt greater than $5 \mathrm{~m} \mathrm{~s}^{-1}$. c Same as (b), but for days with SAt less than $5 \mathrm{~m} \mathrm{~s}^{-1}$. d Mean $700 \mathrm{hPa}$ geopotential height anomaly for days with SAt greater than $5 \mathrm{~m} \mathrm{~s}^{-1}$ but without a high geopotential height anomaly. The approximate geostrophic wind speed associated with the composite anomaly over Southern California is (a) $6 \mathrm{~m} \mathrm{~s}^{-1}$, (b) $8 \mathrm{~m} \mathrm{~s}^{-1}$ (c) $6 \mathrm{~m} \mathrm{~s}^{-1}$ and (d) $4 \mathrm{~m} \mathrm{~s}^{-1}$ (a) SAD mean

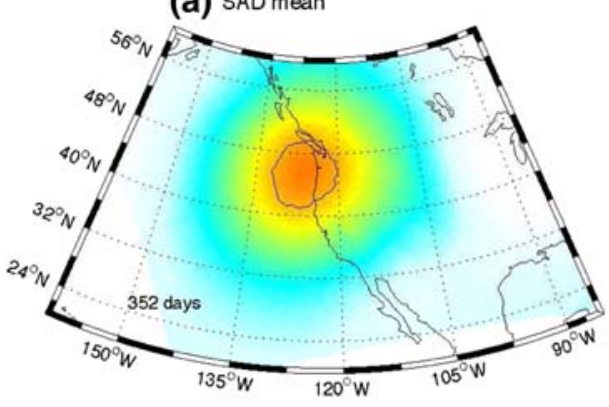

(c) high gph NOT SAD

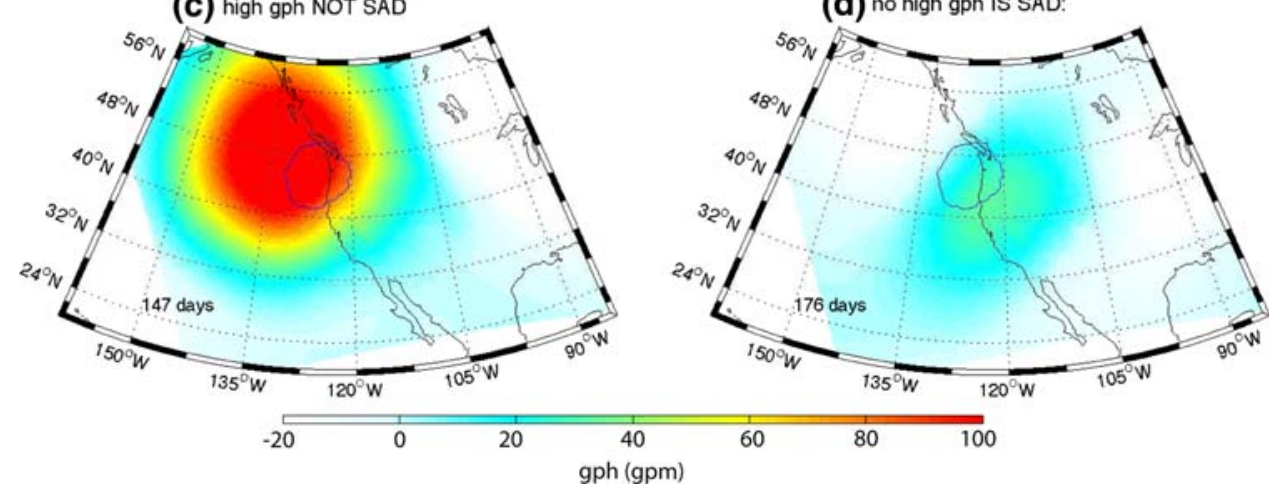

(b) high gph IS SAD:

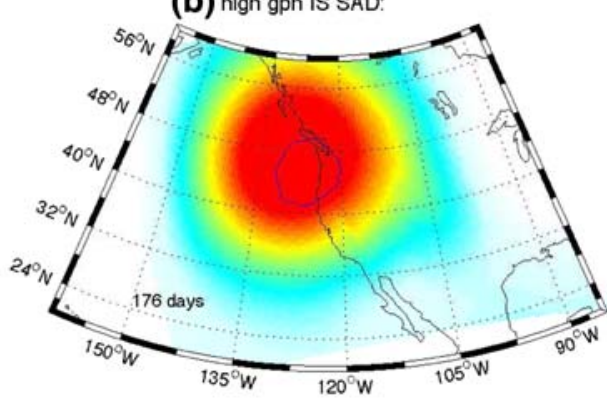

(d) no high gph IS SAD: 


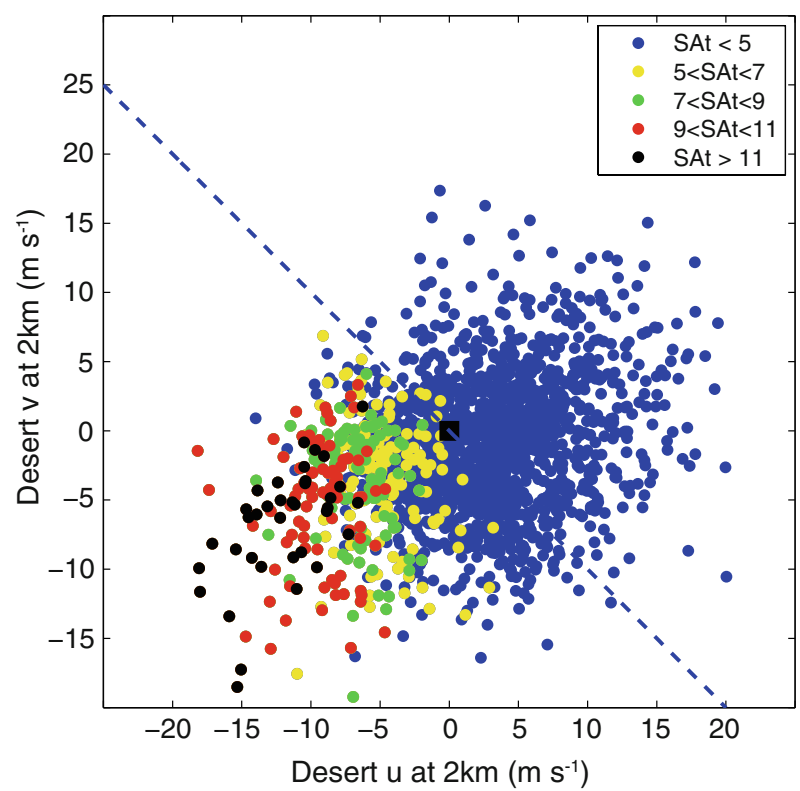

Fig. 6 Scatter plot of $2 \mathrm{~km}$ meridional versus zonal desert winds for all winter days. Dashed line shows $v=-u$, and is perpendicular to the direction used in the construction of SAt. Large black square highlights the origin. Each point is color coded by the strength of SAt as noted by the legend

scale pressure gradient. To illustrate this, we calculate the mean GPH anomaly over the region with the largest SA composite anomaly (Fig. 5, blue line) for each winter day and extract the 280 days with a mean anomaly larger than the SA composite (hereafter these are called high GPH days). We then segregate the high GPH days by the value of SAt (Fig. 5b, c). Only slightly more than half the 280 high GPH days have strong offshore surface winds in Southern California (i.e., SAt $>5 \mathrm{~m} \mathrm{~s}^{-1}$ ), whereas the remaining 123 days have very small SAt. Therefore, when GPH is unusually high, there is nearly a $50 \%$ chance of having weak or no SA winds. Further, half of the SA days (days with SAt $>5 \mathrm{~m} \mathrm{~s}^{-1}$ ) have a GPH anomaly so weak as to be barely discernible on a weather map (Fig. 5d).

If the compositing analysis is repeated for the alongshore GPH gradient, instead of simply the magnitude of the GPH anomaly, the results are similar (not shown): there are many days with a strong pressure gradient and small SAt, as well as the converse. The weakness of the association between the synoptic conditions and the local surface winds is also clear in Fig. 6. There are many days with moderate offshore $2 \mathrm{~km}$ winds over the desert that do not have strong offshore winds at the surface (blue dots in lower left quadrant of Fig. 6), and similarly many days with weak offshore flow aloft and strong offshore surface flow (yellow, green, and red dots near the origin of Fig. 6). Further, SA intensity is not very tightly linked with the strength or direction of the flow aloft, although there is a tendency for the strongest SAs (i.e., SAt $>11 \mathrm{~m} \mathrm{~s}^{-1}$, black dots in Fig. 6) to occur when the $2 \mathrm{~km}$ winds are from the NE. Thus we conclude that the synoptic pressure anomaly and associated gradient, while being a weak predictor of SA occurrence, are not the primary controls on the offshore surface winds in Southern California.

\section{Local thermodynamic effects}

If synoptic forcing is not the primary driver of offshore surface wind strength in Southern California, then what mechanism is dominant? Conil and Hall (2006) found a very strong cold temperature anomaly associated with their SA cluster, suggesting that the desert surface temperature could potentially play a role in their formation. A very cold desert surface temperature could cause strong offshore surface flow by causing a large pressure gradient between the desert surface and the air over the ocean at the same altitude. Cold air would pool in the desert against the lower Sierras and the coastal topography, hydrostatically increasing the desert-ocean pressure gradient, and causing a gravity current to pour through mountain gaps at the surface as the negatively buoyant, cold desert air flowed down the sloped surface of the gaps. The negative buoyancy can be written as a pressure gradient force over the sloping terrain, often called the katabatic pressure gradient force (Parish and Cassano 2003a, b; Mahrt 1982):

$\mathcal{B}=\frac{g \theta^{\prime}}{\theta_{0}} \sin (\alpha)$

where $g=9.8 \mathrm{~m} \mathrm{~s}^{-2}$ is gravitational acceleration, $\theta^{\prime}$ is the temperature deficit of the cold layer, $\theta_{0}$ is the average temperature in the cold layer, and $\alpha$ is the slope of the topography. In our calculation of $\mathcal{B}$, we use the average desert surface air temperature for $\theta_{0}$ and the average slope of the topography through the largest gap for $\alpha$ (approximately 1 degree, or $1 \mathrm{~km}$ drop over $50 \mathrm{~km}$; see Fig. 4a). We calculate $\theta^{\prime}$, the temperature deficit, using the temperature difference between the cold air near the desert surface (i.e., the cold layer) and air over the ocean at the same altitude (representative of the ambient atmosphere). Specific locations used in the definition of $\theta^{\prime}$ are shown in Fig. $8 \mathrm{c}$, although the results are relatively insensitive to the choice of locations.

Figure $7 \mathrm{~b}$ shows the scatterplot of SAt versus $\mathcal{B}$, with points color-coded by the strength of the $2 \mathrm{~km}$ desert winds. There is a strong linear relationship between this pressure gradient force and SAt: as the desert surface gets much colder than the atmosphere over the ocean and $\mathcal{B}$ increases, the strength of the offshore surface winds in Southern California consistently increases. This is further emphasized by the strong correlation between $\mathcal{B}$ and SAt (correlation coefficient $=0.88$ ). If we contrast the SAt $\mathcal{B}$ 

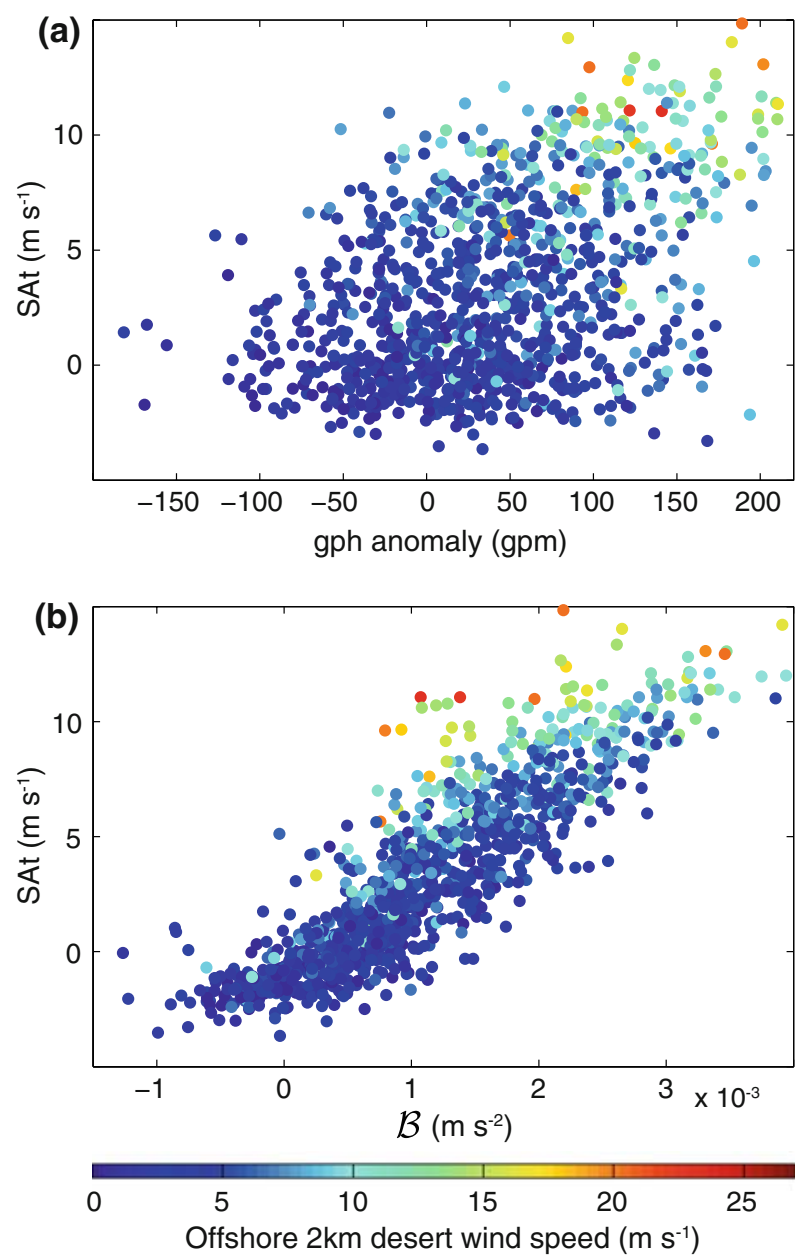

Fig. 7 Santa Ana index versus (a) mean geopotential height anomaly in region shown by blue outline in Fig. 5 and (b) buoyancy-induced pressure gradient force, for winter days when the $2 \mathrm{~km}$ desert winds have an offshore component. The points are color coded by the magnitude of the offshore component of the $2 \mathrm{~km}$ desert wind for each point (reference colorbar is at bottom)

relationship with that between SAt and GPH anomaly (Fig. 7a), we see that although strong GPH anomaly increases the probability of SAt being large, its relationship with SAt is much weaker (correlation coefficient $=0.56$ ). The tight correspondence between $\mathcal{B}$ and SAt, when combined with the weaker relationship between $700 \mathrm{hPa}$ GPH anomaly and SAt, suggests that SAs are driven by a combination of downward momentum transfer from strong upper-level offshore flow and katabatic-type forcing caused by a strong desert-ocean temperature gradient, with the latter being the more important of the two mechanisms.

The two candidate mechanisms drive surface offshore flow through distinct processes. This ought to manifest itself in differences in the vertical structure of the circulation when one mechanism or the other is dominant. We investigate this by conditionally sampling the vertical circulation and temperature structure based on the synoptic conditions and the magnitude of the katabatic pressure gradient force. Figure 8 shows vertical cross sections of potential temperature and page-parallel winds for three composite cases determined by the value of the offshore component of the $2 \mathrm{~km}$ desert wind $(u)$ and $\mathcal{B}$ defined above. The three cases were chosen to correspond to days when synoptic forcing is dominant (large $u$ and small $\mathcal{B}$ ), thermodynamic forcing is dominant (small $u$ and large $\mathcal{B}$ ), and both forcings are present (large $u$ and large $\mathcal{B}$ ). The cross sections transect the largest gap within Southern California (Fig. 4a).

Examining the winds in Fig. 8, we see that the synoptically-forced cases have fairly weak winds at the lowest elevations, despite having nearly the same wind strength above the desert surface as the case with both forcings. Although this could in part be due to less downward transport of horizontal momentum in the less stable, small $\mathcal{B}$ case, it seems more likely that it is the lack of katabatic forcing causing the slow wind speeds at low elevations. Comparing the thermodynamically-forced case with its converse (Fig. 8a, c) reveals a notable difference in the height-profile of the wind between the two cases. The synoptically-forced composite has strong surface winds only where the elevation drops-everywhere else the wind speed decays as height decreases. In contrast, the thermodynamically-forced composite has moderate surface winds through nearly the entire gap, with these winds almost entirely trapped within the lowest $500 \mathrm{~m}$ of atmosphere.

The circulation contrasts among these three cases can be seen even more clearly in a vertical profile of offshore winds averaged over the ocean leeward of the gap located between the San Gabriel and Tehachapi mountains (Fig. 9). The synoptically-forced composite has strong offshore winds aloft but very weak winds at the surface, whereas the thermodynamically-forced composite shows an offshore surface wind despite nearly zero velocity aloft. The composite for days with both forcings is nearly a linear combination of these two cases, with strong offshore flow aloft paired with extremely strong flow at the surface. This is compelling evidence that the downward momentum transfer and katabatic forcing mechanisms are nearly superposable, an idea we explore further in Sect. 6.

The composite $10 \mathrm{~m}$ winds in the entire $6 \mathrm{~km}$ domain for the three composites (Fig. 10) reveals how closely each case resembles the SA cluster surface wind pattern (Fig. 4a). The synoptically-forced composite (Fig. 10c) shows moderate offshore winds in the lee of most of the coastal topography and through the gaps, with very weak winds at the lowest-elevation, coastal regions. This is what we expect given strong upper-level flow but inefficient downward momentum transfer, since the higher-elevation mountains are closer to the mid-level momentum source. The thermodynamically-forced composite (Fig. 10b) more 


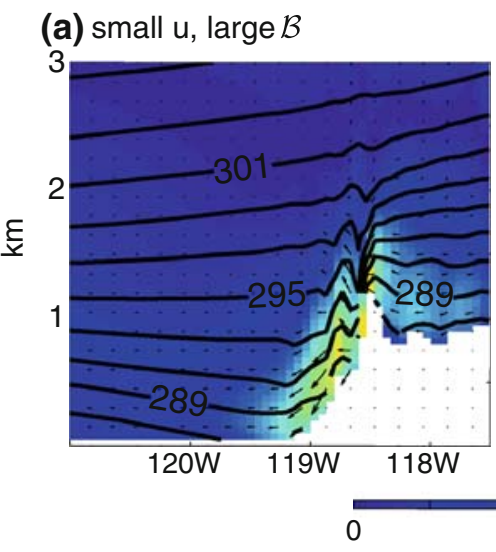

(b) large $u$, large $\mathcal{B}$

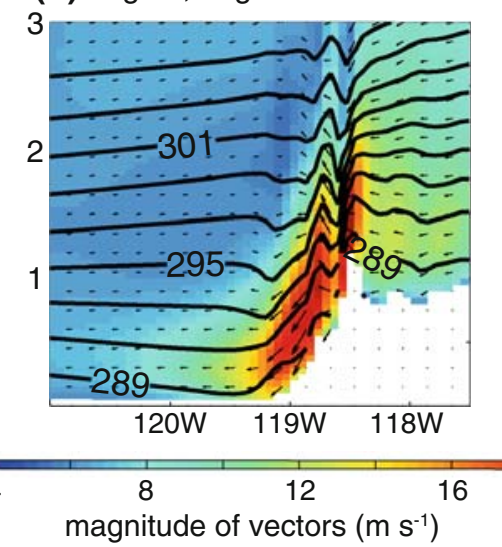

(c) large $u$, small $\mathcal{B}$

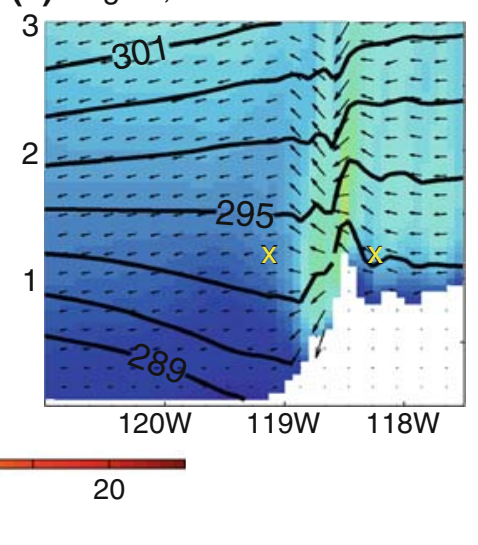

Fig. 8 Composite vertical cross section of wind speed (color contours), potential temperature (black contours, every $2 \mathrm{~K}$ ) and wind (arrows) for days with (a) $u<2.5 \mathrm{~m} \mathrm{~s}^{-1}$ and $\mathcal{B}>0.0018 \mathrm{~m} \mathrm{~s}^{-2}$, (b) $u>5.5 \mathrm{~m} \mathrm{~s}^{-1}$ and $\mathcal{B}>0.0018 \mathrm{~m} \mathrm{~s}^{-2}$ and $(\mathbf{c}) u>5.5 \mathrm{~m} \mathrm{~s}^{-1}$ and $\mathcal{B}<0.00075 \mathrm{~m} \mathrm{~s}^{-2}$, where $u$ is the offshore component of the $2 \mathrm{~km}$

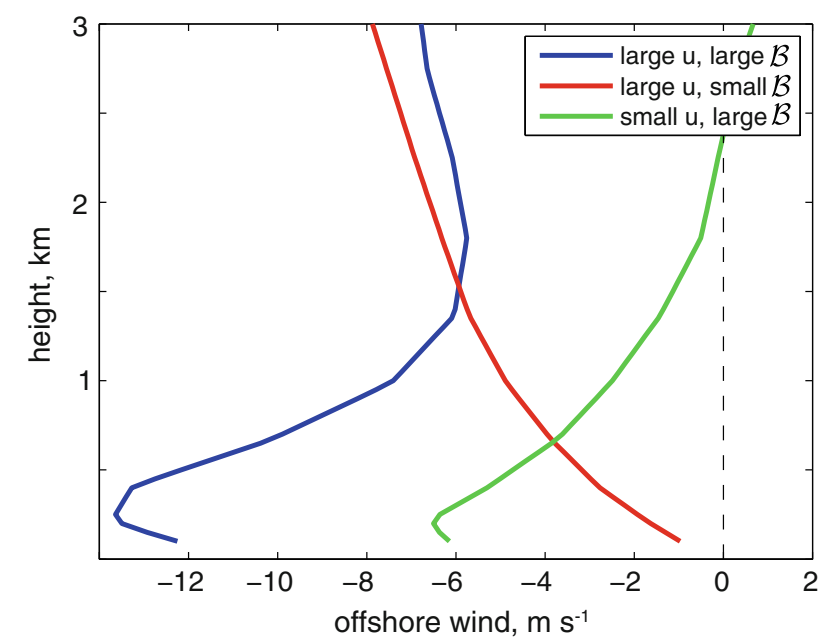

Fig. 9 Vertical profile of offshore wind strength for three cases shown in Fig. 8, averaged over 119.7-119.1W. Thin dashed black line shows the origin

closely resembles the SA composite (Fig. 4a), despite the lack of synoptic forcing: There are moderately strong offshore winds through the three major $\mathrm{N}-\mathrm{S}$ gaps in the topography that extend southwest over the ocean and offshore flow along the Santa Ynez mountains. The flow over the San Gabriel and San Bernardino mountains is small, a reflection of the shallowness of this circulation. Finally, the dual-mechanism composite (Fig. 10a) almost exactly resembles the SA composite (Fig. 4a), except that the winds everywhere are a bit stronger (note differing colorbars). The combination of a surface gravity current and downward momentum transfer of offshore upper level winds gives rise to unusually strong SA winds on these days. desert winds, and $\mathcal{B}$ is the buoyancy-induced pressure gradient force. Location of cross section is shown in Fig. 4 as line BB. The aspect ratio of each panel is approximately 1:100 (vertical:horizontal), and the vertical velocity is scaled accordingly. Yellow $x$ 's in panel $c$ show locations used to calculate $\theta^{\prime}$ in Eq. 1

Comparing the potential temperature in panels with large and small $\mathcal{B}$ (i.e. Fig. $8 \mathrm{a}$ and $\mathrm{b}$ with $\mathrm{c}$ ), the most obvious difference is that the former have much colder temperatures at the desert surface, which explains the cold desert-temperature anomalies seen by Conil and Hall (2006). Curiously, the desert surface temperature is only weakly correlated (approximately 0.4 ) with SAt, indicating the atmospheric temperature over the ocean also plays a significant role in determining variability in the katabatic pressure gradient force, and the panels of Fig. 8 reveal why: the air temperature $1.2 \mathrm{~km}$ over the ocean is nearly 3 degrees warmer in the large $\mathcal{B}$ composites than in the small $\mathcal{B}$ composite.

\section{A bivariate regression model of SAt}

The results of Sects. 4 and 5 suggest that both $u$ and $\mathcal{B}$ play a role in determining SA intensity. We now quantify these two roles for winter days when the mid-level winds are weak to strongly offshore using a bivariate regression model for SAt, with $u$ and $\mathcal{B}$ as the two independent variables. The resulting equation for SAt predicted by the regression is:

$\widehat{\operatorname{SAt}}(u, \mathcal{B})=A * u+B * \mathcal{B}+C$

where $A=0.34 \mathrm{~s} \mathrm{~m}^{-1}, B=3,100 \mathrm{~s}^{-2} \mathrm{~m}^{-1}$, and $C=$ $-1.88 \mathrm{~m} \mathrm{~s}^{-1}$. Figure 11 shows the result of the regression model plotted against actual SAt for winter days when the upper level flow is offshore. The regression model accurately captures almost all variability in SAt, illustrated quantitatively by the extremely high correlation coefficient between SAt and $\widehat{S A t}(0.93)$. 
(a) large $u$, large $\mathcal{B}$

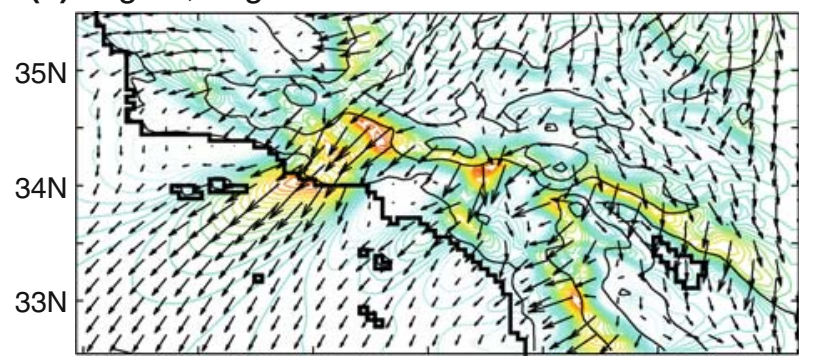

(b) small $u$, large $\mathcal{B}$

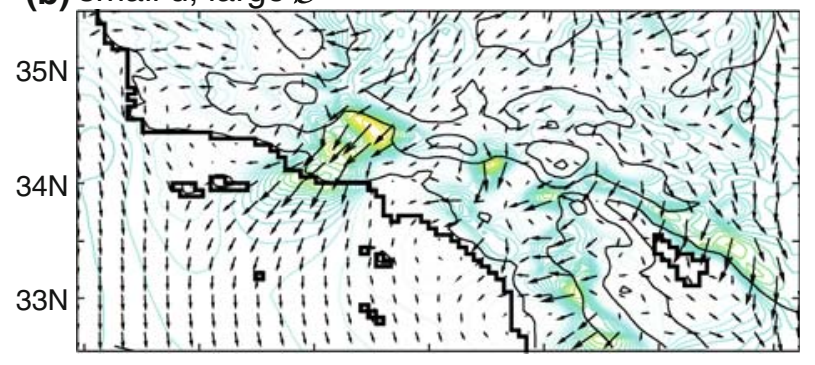

(c) large $u$, small $\mathcal{B}$

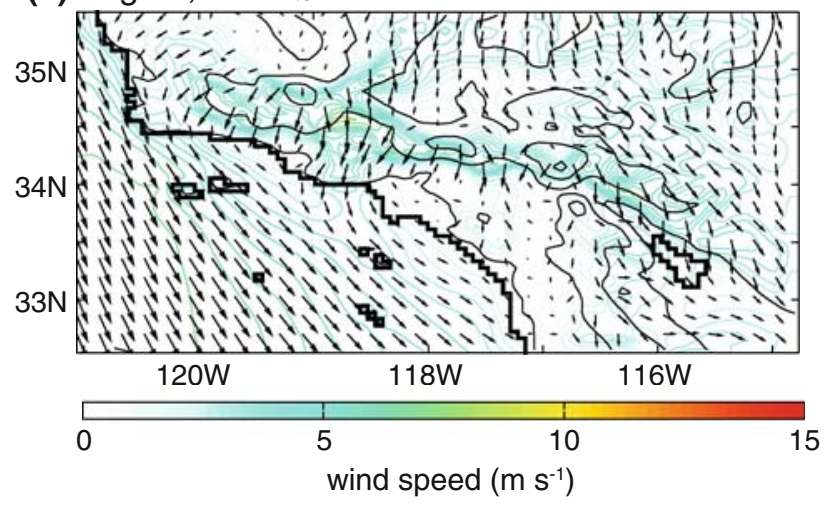

Fig. 10 Surface winds (arrows) and wind speeds (color contours, $\mathrm{m}$ $\mathrm{s}^{-1}$ ) for days with (a) $u>5.5 \mathrm{~m} \mathrm{~s}^{-1}$ and $\mathcal{B}>0.0018 \mathrm{~m} \mathrm{~s}^{-2}$, (b) $u<2.5 \mathrm{~m} \mathrm{~s}^{-1}$ and $\mathcal{B}>0.0018 \mathrm{~m} \mathrm{~s}^{-2}$ and (c) $u>5.5 \mathrm{~m} \mathrm{~s}^{-1}$ and $\mathcal{B}<0.00075 \mathrm{~m} \mathrm{~s}^{-2}$, where $u$ is the offshore component of the $2 \mathrm{~km}$ desert winds, and $\mathcal{B}$ is the buoyancy-induced pressure gradient force. Black contours show terrain and coastline as in Fig. 3

The regression model's high degree of fidelity means we can use it to untangle the controls on SAt variability. The variance of SAt accounted for by $u, \mathcal{B}$, the covariance term and the regression model error is shown in Table 1; the variance is calculated by squaring Eq. 2 after subtracting its mean. The regression model clarifies an aspect of SA dynamics we were unable to address with Fig. 7, namely the tendency for large $\mathcal{B}$ and $u$ to occur simultaneously. The two may co-vary for two reasons: First, strong synoptically-driven downslope flow would depress isentropes on the lee- (i.e., coastal) side of the mountains, increasing the likelihood of warm over-ocean temperatures, and therefore increasing the desert-ocean temperature difference and katabatic pressure gradient force. Second, strong

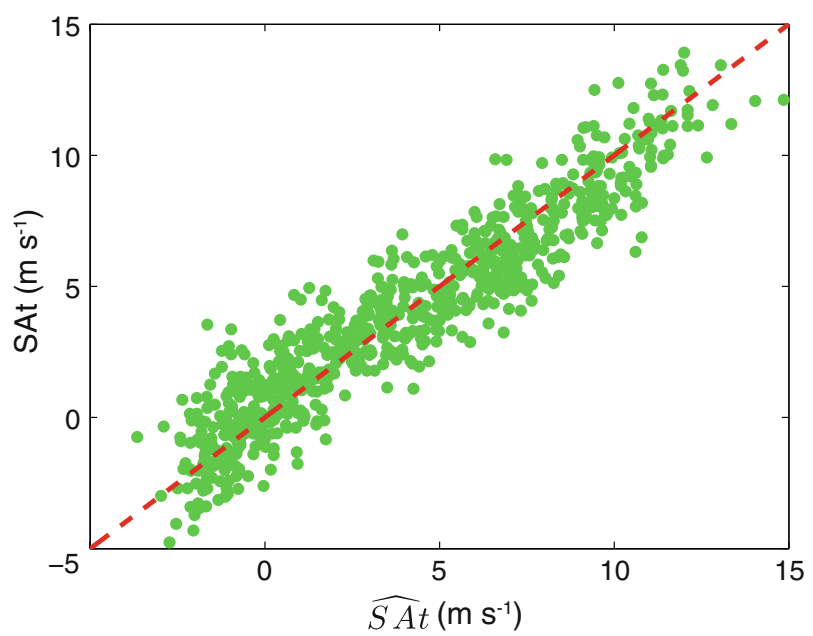

Fig. 11 Santa Ana index versus SAt predicted by the multivariate regression model described in Sect. 6. Dashed red line shows $\mathrm{SAt}=\widehat{S A t}$

offshore flow at two kilometers is likely to cause cold advection into the desert, similarly enhancing the katabatic pressure gradient force. This tendency is represented by the covariance term in the regression model variance (third column of Table 1). The covariance of $u$ and $\mathcal{B}$ accounts for approximately $23 \%$ of the variance in SAt, indicating that it significantly contributes to the likelihood of strong offshore winds. More notable, however, is the large amount of variance explained by variations in $\mathcal{B}$ independent of $u$ $(51 \%)$. This is double the variance accounted for by any other single term. This indicates that unless synoptic conditions are unfavorable for the development of SAs (i.e., onshore), strong offshore surface flow often develops due only to katabatic forcing.

\section{Conclusions}

We investigate the atmospheric conditions that lead to Santa Ana winds using the North American Regional Reanalysis and a 12-year, 6-km resolution regional climate simulation of Southern California. A SA index is constructed by averaging the offshore component of the surface winds at the exit of the largest gap in the region's topography. This index shows strong seasonality consistent with previous measures of Santa Ana wind occurrence.

This index is then used to identify the average synoptic conditions associated with Santa Ana events. Compositing

Table 1 Variance explained by each of the terms of the bivariate regression $(u, \mathcal{B}$, covariance, and error $)$

\begin{tabular}{llll}
\hline$u$ & $\mathcal{B}$ & Covariance & Error \\
\hline $12 \%$ & $51 \%$ & $23 \%$ & $14 \%$ \\
\hline
\end{tabular}


reveals a high pressure anomaly at $700 \mathrm{hPa}$ centered over the west coast of the United States. The composite pressure anomaly would cause strong offshore geostrophic winds roughly perpendicular to the mountain ranges; an inspection of the $2 \mathrm{~km}$ desert winds incident on the topography shows that many of the strongest Santa Ana days have strong winds in this direction. These strong offshore winds make strong surface winds more likely through gravity wave transfer of mid-level momentum to the surface. We find, however, that there are large variations in the synoptic conditions during Santa Ana conditions, and that there are many days with strong offshore flow and weak synoptic forcing. This is because of local thermodynamic forcing that causes strong offshore surface flow: a large temperature gradient between the cold desert surface and the warm ocean air at the same altitude causes an offshore pressure gradient at that altitude. This in turn causes strong offshore flow in a thin layer near the surface.

We quantify the contribution of these two mechanisms using a bivariate linear regression model, with mid-tropospheric offshore wind speed over the desert, $u$, and the katabatic pressure gradient force arising from the local temperature gradient, $\mathcal{B}$, as independent variables. The regression model allows us to quantify the contribution to SAt variability from $u, \mathcal{B}$, and a covariance term, which arises because the synoptic conditions favorable for large SAt (i.e., strong mid-level offshore winds) also favor the development of strong $\mathcal{B}$ because they often cause lee-side isentrope depression, warming the over-ocean air, or because they favor cold air advection into the desert. This model almost perfectly represents variability in SAt, and reveals that the local thermodynamic forcing is the primary control on Santa Ana variability. Over 50\% of the variance of SAt is due to $\mathcal{B}$ for days with weak or offshore synoptic conditions, with the remaining half of the variance distributed among $u$, the covariance term, and the error of the regression model.

The identification of the processes responsible for SA development allows us to understand the large discrepancy between the NARR and MM5 offshore winds at the exit of the largest gap in the topography (Fig. 1). NARR cannot accurately resolve the slopes of the coastal topography, and also most likely cannot resolve the tight temperature gradient that can develop between the desert and ocean atmosphere. This possibly results in the katabatic pressure gradient force being absent in the NARR dynamics, which would explain why the offshore surface winds are much too slow when $\mathcal{B}$ is large (see colorbar, Fig. 1).

In addition, the large proportion of SAt variability due to local thermodynamic processes probably explains the curious seasonal cycle of SA events: The December maximum in SA events occurs 2 months earlier than the maximum climatological poleward transport of eddy heat fluxes (Hartmann 1994) and of precipitation (a local indicator of frontal passage) in Southern California (e.g., Conil and Hall 2006). However, an inspection of the annual cycle of desert surface temperature and air temperature $1.2 \mathrm{~km}$ over the ocean (not shown) reveals that December is precisely the month when the climatology of temperature favors development of a strong temperature gradient. At this time, the desert surface is coldest relative to the air over the ocean. Thus the probability of large katabatic forcing is also largest in December.

Finally, this study reveals why Santa Ana wind occurrence is so weakly related to larger scale modes of variability (Conil and Hall 2006; Raphael 2003). Only half the variance in SAt is attributable to large scale controls, with the other half due to a local pressure gradient generated by the temperature contrast between the cold desert surface and the air over the ocean at the same altitude, probably due to a combination of local and large-scale processes. Since the desert temperature will probably increase more quickly in the transient response to increases in greenhouse gases than the air over the ocean, SA frequency and intensity will potentially be reduced in the coming decades. Further, the seasonality of SA occurrence is probably strongly constrained by this temperature gradient mechanism, and could also be altered in a changing climate. Both of these effects have strong implications for future wild fire frequency in an ever more densely populated Southern California. These ideas are being tested in a regional downscaling of future climate represented by a global general circulation model.

Acknowledgments Mimi Hughes is supported by the UCLA Dissertation Year Fellowship and NSF ATM-0735056, which also supports Alex Hall. Part of this work was performed using NCAR supercomputer allocation 35681070 . The authors would like to thank two anonymous reviewers, whose comments greatly improved the manuscript.

Open Access This article is distributed under the terms of the Creative Commons Attribution Noncommercial License which permits any noncommercial use, distribution, and reproduction in any medium, provided the original author(s) and source are credited.

\section{References}

Ball F (1956) The theory of strong katabatic winds. Aust J Phys 9:373-386

Barry RG (1992) Mountain weather and climate. Routledge, London, p 402

Castro R, Mascarenhas A, Martinez-Diaz-de Leon A, Durazo R, GilSilva E (2006) Spatial influence and oceanic thermal response to Santa Ana events along the Baja California peninsula. Atmosfera 19:195-211

Conil S, Hall A (2006) Local regimes of atmospheric variability: a case study of Southern California. J Clim 19:4308-4325 
Dudhia J (1989) Numerical study of convection observed during the winter monsoon experiment using a mesoscale two-dimensional model. J Atmos Sci 46:3077-3107

Durran DR (1990) Mountain waves and downslope winds. Atmospheric processes over complex terrain. Meteor Monogr No. 45, Am Meteor Soc. pp 59-82

Gaberšek S, Durran DR (2004) Gap flows through idealized topography. Part I: forcing by large-scale winds in the nonrotating limit. J Atmos Sci 61:2846-2862

Gaberšek S, Durran DR (2006) The dynamics of gap flow over idealized topography: part II. Effects of rotation and surface friction. J Atmos Sci 63:2720-2739

Grell G, Dudhia J, Stauffer D (1994) A description of the fifthgeneration Penn State/NCAR Mesoscale Model (MM5). Tech. rep., NCAR Tech. Note NCAR/TN-398+STR

Hartmann DL (1994) Global physical climatology. Academic Press, San Diego, pp 411

Hong S, Pan H (1996) Nonlocal boundary layer vertical diffusion in a medium-range forecast model. Mon Weather Rev 124:23222339

Hu H, Liu W (2003) Oceanic thermal and biological responses in Santa Ana winds. Geophys Res Lett 30:1596. doi:10.1029/ 2003GL017208

Hughes M, Hall A, Fovell R (2007) Dynamical controls on the diurnal cycle of temperature in complex topography. Clim Dyn 29:277292. doi:10.1007/s00382-007-0239-8

Jickells T, An ZS, Andersen KK, Baker AR, Bergametti G, Brooks N, Cao JJ, Boyd PW, Duce RA, Hunter KA, Kawahata H, Kubilay N, laRoche J, Liss PS, Mahowald N, Prospero JM, Ridgwell AJ, Tegen I, Torres R (2005) Global iron connections between desert dust, ocean biogeochemistry, and climate. Science 308:67-71. doi:10.1126/science. 1105959

Kain JS (2002) The Kain-Fritsch convective parameterization: an update. J Appl Meteor 43:170-181

Klemp JB, Lilly DK (1975) The dynamics of wave-induced downslope winds. J Atmos Sci 32:320-339
Mahrt L (1982) Momentum balance of gravity flows. J Atmos Sci 39:2701-2711

Mesinger F, DiMego G, Kalnay E, Mitchell K, Shafran P, Ebisuzaki W, Jovi D, Woollen J, Rogers E, Berbery EH, Ek M, Fan Y, Grumbine R, Higgins W, Li H, Lin Y, Manikin G, Parrish D, Shi W (2006) North American regional reanalysis. Bull Am Meteor Soc 87:343-360

Miller NL, Schlegel NJ (2006) Climate change projected fire weather sensitivity: California Santa Ana wind occurrence. Geophys Res Lett 33. doi:10.1029/2006GL025808

Parish T, Cassano J (2003a) Diagnosis of the katabatic wind influence on the wintertime Antarctic surface wind field from numerical simulations. Mon Weather Rev 131:1128-1139

Parish T, Cassano J (2003b) The role of katabatic winds on the Antarctic surface wind regime. Mon Weather Rev 131:317-333

Raphael MN (2003) The Santa Ana winds of California. Earth Interact 7:1-13

Schroeder MJ, Glovinsky M, Krueger DW, Hendricks VF, Mallory LP, Hood FC, Oertel AG, Hull MK, Reese RH, Jacobson HL, Sergius LA, Kirkpatrick R, Syverson CE (1964) Synoptic weather types associated with critical fire weather. Tech. rep., Berkeley, Calif., Pacific SW Forest and Range Exp. Sta., Forest Service-U.S. Department of Agriculture

Smith R (1979) The influence of the mountain on the atmosphere. Adv Geophys 21:87-230

Smith R (1985) On severe downslope winds. J Atmos Sci 42:25972603

Sommers WT (1978) LFM forecast variables related to Santa Ana wind occurrences. Mon Weather Rev 106:1307-1316

Trasviña A, Ortiz-Figueroa M, Herrera H, Coso MA, Gonzlez E (2003) Santa Ana winds and upwelling filaments off Northern Baja California. Dyn Atmos Oceans 37:113-129

Westerling AL, Cayan DR, Brown TJ, Hall BL, Riddle LG (2004) Climate, Santa Ana winds and autumn wildfires in Southern California. EOS 85:289-296 